\title{
February 10 Highlights
}

\section{Screening for new aneurysms after subarachnoid hemorrhage}

In a decision model that assessed the risks/benefits of screening for new aneurysms after successful treatment of SAH, Wermer et al. showed that complications from preventive treatment outweighed the benefits from preventing new episodes of SAH. Because of the limited data on key factors in the model, is possible that more empirical data may change the balance.

see page 369

The accompanying editorial by Brown and Piepgras emphasizes that the model suggests that the overall screening for new aneurysms after SAH does not lead to an increased number of quality-adjusted life years. However, among the factors that had the most marked impact on outcome were the risk of arteriography and treatment-both likely to change with advances in techniques. They also note that where the risk is higher than usual-such as among families with two or more members who previously had a SAH or intracranial aneurysm - "one size does not fit all" for aneurysm screening any more than it does for aneurysm management.

see page 354

\section{Role of $D J-1$ and Parkin in Parkinson disease}

To evaluate the importance of mutations in $D J-1$ and Parkin in early-onset Parkinson disease (EOPD), Hedrich et al. screened both genes for small sequence changes and exon deletions/multiplications in 100 EOPD patients. Whereas alterations in $D J-1$ were rare (two heterozygous mutations), $17 \%$ of EOPD cases were Parkin mutation carriers.

see page 389

The accompanying editorial by $O$. Bandmann notes that although DJ-1 mutations are rare and less common than Parkin mutations, they are nevertheless more common than mutations in other PD genes such as alpha-synuclein. Typical clinical features of DJ-1 positive patients are slow disease progression and good, prolonged response to L-dopa. DJ-1 encodes a ubiquitous, highly conserved protein. It is involved in the response to oxidative stress and in transcription regulation. The precise mechanism as to how loss of DJ-1 function leads to neuronal cell death in the substantia nigra remains to be elucidated. The Hedrich et al. article raises the intriguing possibly that a single DJ-1 mutation may sometimes be sufficient to cause $P D$, presumably in combination with other genetic or exogenous factors.

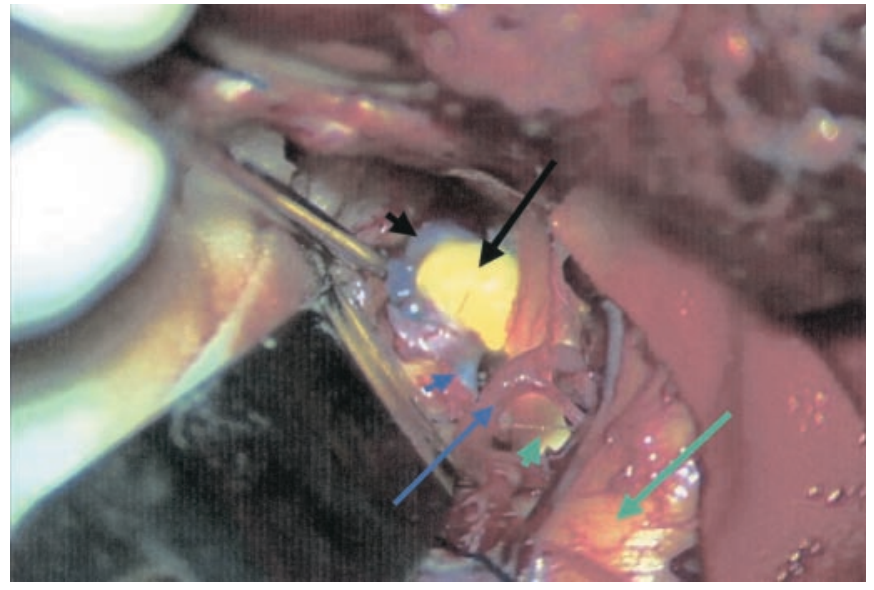

A 10-mm bilobed anterior communicating artery aneurysm. One lobe contains atherosclerosis (long black arrow) and the other is seen behind (small black arrow). The A1 segment (small blue arrow) enters the aneurysm base. The middle cerebral artery is in the foreground (long blue arrow). The right optic nerve is also seen (short green arrow). The temporal lobe (long green arrow is being retracted), allowing visualization of the aneurysm in the Sylvian fissure.

\section{Memory and familial Alzheimer disease}

Lee et al. report that genetic factors, independent of APOE, contribute approximately $40 \%$ to $60 \%$ of the variation in declarative memory and related cognitive measures in families where multiple individuals have Alzheimer disease (AD). Because memory decline is the single most consistent clinical manifestation of the disease, identifying genes that influence memory in individuals with familial $\mathrm{AD}$ may help identify additional genes that cause $\mathrm{AD}$.

see page 414

\section{Obstructive sleep apnea, cerebral hypoxemia, and death}

Dyken et al. polysomnographically document obstructive sleep apnea leading to cerebral hypoxemia, with subsequent severe but reversible transient encephalopathy, in one patient and death in another.

see page 491 


\section{DWI abnormalities in TIA patients}

Inatomi et al., in a prospective study, performed MRI DWI in 129 patients within 14 days of TIA onset. A multiple logistic regression model demonstrated that prolonged TIA duration and disturbance of higher brain function are independent factors that correlate with DWI abnormalities.

see page 376

The accompanying editorial by Warach and Kidwell notes that numerous studies now have demonstrated that almost half of patients with clinical TIA have a DWI abnormality. What once was considered a meaningful distinction based on duration of deficits and implied a benign course and prognosis is now recognized as a part of the spectrum of acute cerebrovascular disease and as much of an emergency. The recommended work-up and management of TIA is indistinguishable from that of cerebral infarction.

see page 359

\section{Functional $M x A$ polymorphism associated with subacute sclerosing panencephalitis}

Torisu et al. found in association studies between a functional $M x A$ promoter -88G/T polymorphism andsubacute sclerosing panencephalitis that SSPE patients had a significantly higher frequency of -88TT genotype than controls. The $M x A$ promoter polymorphism could confer host genetic susceptibility to SSPE.

see page 457
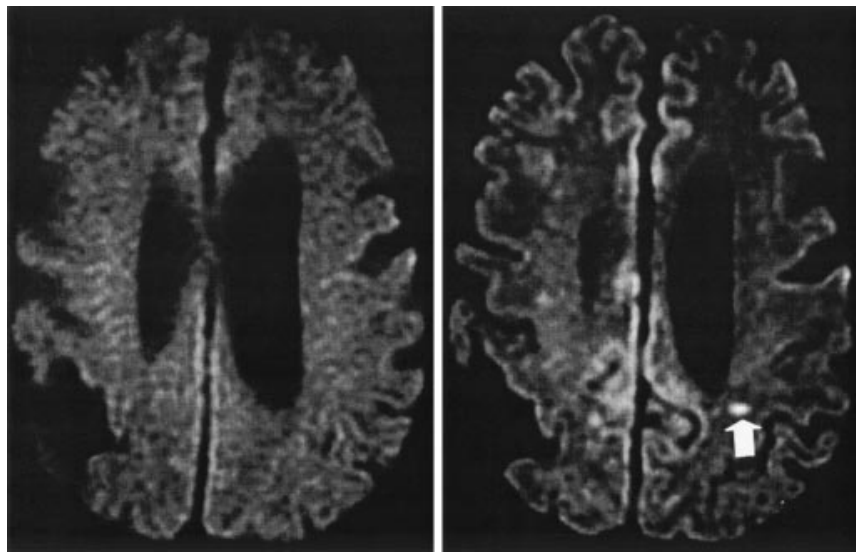

Negative scan with standard DWI sequence; positive with higher resolution/signal to noise

\section{Vibration testing with a quantitative tuning fork}

Pestronk et al. found that quantitative tuning fork measurements in 184 patients were better correlated with SNAP amplitudes than standard qualitative vibration testing. Quantitative tuning fork testing is rapid, reliable, and objective, and provides information about more body regions than usual qualitative methods.

see page 461 


\section{Neurology}

February 10 Highlights

Neurology 2004;62;350-351

DOI 10.1212/WNL.62.3.350

This information is current as of February 9, 2004

\section{Updated Information \&} Services

Permissions \& Licensing

Reprints including high resolution figures, can be found at: http://n.neurology.org/content/62/3/350.full

Information about reproducing this article in parts (figures,tables) or in its entirety can be found online at:

http://www.neurology.org/about/about_the_journal\#permissions

Information about ordering reprints can be found online:

http://n.neurology.org/subscribers/advertise

Neurology ${ }^{\circledR}$ is the official journal of the American Academy of Neurology. Published continuously since 1951, it is now a weekly with 48 issues per year. Copyright . All rights reserved. Print ISSN: 0028-3878. Online ISSN: 1526-632X.

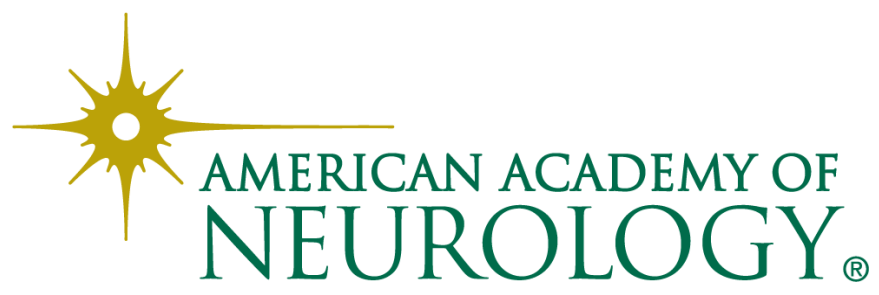

